\title{
Clinical Characterization of the Frequent Exacerbator Phenotype in Asthma
}

\author{
Andrea Elio Sprio ${ }^{1}{ }^{1}$, Vitina Carriero ${ }^{1}$, Stefano Levra ${ }^{1}$, Carlotta Botto ${ }^{1}$, Francesca Bertolini ${ }^{1}$, \\ Antonino Di Stefano ${ }^{2}$ (D), Mauro Maniscalco ${ }^{3}(\mathbb{D})$, Giorgio Ciprandi ${ }^{4}$ (D) \\ and Fabio Luigi Massimo Ricciardolo ${ }^{1, *}$ \\ 1 Department of Clinical and Biological Sciences, University of Turin, San Luigi Gonzaga University Hospital, \\ Orbassano, 10043 Turin, Italy; andrea.sprio@unito.it (A.E.S.); vitina.carriero@unito.it (V.C.); \\ stefano.levra@unito.it (S.L.); carlotta.botto88@gmail.com (C.B.); francesca.bertolini@unito.it (F.B.) \\ 2 Department of Pneumology and Laboratory of Cytoimmunopathology of the Heart and Lung, \\ Istituti Clinici Scientifici Maugeri SpA, IRCCS, Veruno, 28010 Novara, Italy; \\ antonino.distefano@icsmaugeri.it \\ 3 Pulmonary Rehabilitation Unit, Istituti Clinici Scientifici Maugeri SpA, IRCCS, Telese Terme, \\ 82037 Benevento, Italy; mauromaniscalco@hotmail.com \\ 4 Allergy Clinic, Casa di Cura Villa Montallegro, 16145 Genoa, Italy; gio.cip@libero.it \\ * Correspondence: fabioluigimassimo.ricciardolo@unito.it; Tel.: +39-011-9026777
}

Received: 15 June 2020; Accepted: 10 July 2020; Published: 14 July 2020

check for updates

\begin{abstract}
Background: Asthma exacerbation is episodic worsening of respiratory symptoms in conjunction with the deterioration of lung function, which may occur independently from the asthma severity hampering asthmatics' quality of life. This study aimed to characterize the patient phenotype more prone to asthma exacerbation (oral corticosteroid burst $\geq 2$ per year) to allow the proper identification of such patients. Methods: This real-life, observational, cross-sectional study evaluated 464 asthmatic patients stratified according to the asthma exacerbations experienced in the previous year. Clinical, functional, and blood parameters were retrieved from chart data and were representative of patients in stable conditions. Results: The frequent asthma exacerbator was more commonly female, suffered from chronic rhinosinusitis with nasal polyposis, had reduced lung function and peripheral oxygen saturation, and had increased daily activity limitations. These patients often had severe asthma and more frequently needed hospitalization in their lives. Furthermore, the frequent asthma exacerbator had higher concentrations of serum immunoglobulin E (IgE) and exhaled nitric oxide with cut-off risk values of $107.5 \mathrm{kU} / \mathrm{L}(\mathrm{OR}=4.1)$ and $43.35 \mathrm{ppb}(\mathrm{OR}=3.8)$, respectively. Conclusions: This study illustrates the clinical features of the frequent asthma exacerbator phenotype. Nevertheless, serum IgE and exhaled nitric oxide could allow the identification of this phenotype and the establishment of an appropriate therapeutic approach.
\end{abstract}

Keywords: asthma; airway obstruction; nasal polyps; nitric oxide; IgE

\section{Introduction}

Asthma is a heterogeneous disorder characterized by chronic complex inflammatory status and reversible airflow obstruction. This respiratory condition displays episodic worsening of respiratory symptoms in conjunction with a deterioration of lung function (so-called asthma exacerbation (AE)), which requires changes in treatment to reacquire asthma control [1]. The AE is defined as severe when it necessitates the use of systemic corticosteroids for at least three days, whereas it is defined as serious when emergency department/hospital admission occurs and the condition eventually requires mechanical ventilation [1,2]. The latter is considered a life-threatening event, representing 
the leading cause of morbidity and mortality related to asthma. In this context, the occurrence of $\mathrm{AE}$ reduces the patient's quality of life significantly, inducing a state of stress, anxiety, and fear [3].

Furthermore, AE has a substantial economic impact on the healthcare system, as it is responsible for a considerable portion of the annual economic burden correlated with asthma [3]. A previous report estimated that the uncontrolled asthma patient costs about four times more than a well-controlled one [4]. Therefore, understanding the factors related to the development of exacerbations must be considered of great socioeconomic importance.

$\mathrm{AE}$ is a common feature of patients affected by severe asthma [5], a condition that requires a high dose of inhaled corticosteroids plus a second controller (and/or systemic corticosteroids) [2,6]. Thereby, the literature describes different aspects and characteristics of these patients. Phenotype and endotype classifications have been provided based on the involved inflammatory response, immune mediators, or molecular mechanisms $[7,8]$.

The frequency of AE is positively correlated to high counts in sputum and blood eosinophils [9-12], and therapies against type-2 immune response mediators showed efficacy in reducing the AE rate [13]. However, discrepancies in these correlations suggest that the exacerbation rate could not be strictly associated with systemic type-2 inflammation [14]. Indeed, higher neutrophil counts in both sputum and blood of asthmatic patients with exacerbations are reported in the literature [15,16]. A dual immune response mediated by both type-2 and non-type- 2 cytokines has been proposed [17] and linked with exacerbation in the severe asthmatic patient [18].

Nevertheless, AE can be experienced irrespectively of asthma severity [19]. In this context, the analysis of phenotypes based on exacerbation frequency is required. Thus far, the literature has lacked a systematic study on the risk of developing AE. We analyzed a large cohort of patients affected by mild to severe asthma in a real-world setting and stratified them according to the AE frequency, seeking to describe the main features and risks correlated to the frequent exacerbator phenotype.

\section{Methods}

\subsection{Patients}

This real-life, observational, cross-sectional study, which ended in September 2019, evaluated chart data from 464 asthmatic patients who were referred to the "Chronic Obstructive Pulmonary Disease and Severe Asthma" Service at the San Luigi Gonzaga University Hospital (Orbassano, Torino, Italy).

The inclusion criterion was the confirmed diagnosis of mild to severe asthma according to the Global Initiative for Asthma (GINA) and ERS/ATS guidelines [2,20]. All analyses were only performed on patients without AE symptoms and in stable condition. All the patients were optimally treated. On each visit, self-reported adherence to inhaled therapy (including inhaled corticosteroids (ICS)) was questioned, and the inhalation technique was checked. The prescribed ICS dose was adjusted for the percentage of self-reported therapy adherence and then recorded. In this study, patients with poor adherence $(<50 \%)$ or with poor inhalation technique were excluded because of the low reliability of their data and to ensure the evaluation of only optimally treated patients.

This study was performed following the Declaration of Helsinki and approved by the San Luigi Gonzaga University Hospital Review Board (Prot. No. 4478/2017). All participants provided written informed consent.

\subsection{Study Design and Setting}

Patients were stratified based on their severe AE frequency in the year $(\mathrm{AE} / \mathrm{y})$ preceding the last visit. We considered episodes of severe $\mathrm{AE}$ to be those requiring systemic corticosteroid (CS) bursts for more than three consecutive days [2]. In a first instance, we used the cut-off of $2 \mathrm{AE} / \mathrm{y}$; a patient with $<2 \mathrm{AE} / \mathrm{y}$ was classified as a nonfrequent exacerbator ( $\mathrm{nFE} ; n=367)$, whereas a patient who experienced $\geq 2 \mathrm{AE} / \mathrm{y}$ was classified as frequent exacerbator $(\mathrm{FE} ; n=97)[11,21]$. Then, we further subdivided these 
categories into non- $(\mathrm{NE} ; \mathrm{AE} / \mathrm{y}=0, n=248)$, occasional $(\mathrm{OE} ; \mathrm{AE} / \mathrm{y}=1, n=119)$, mildly frequent (mFE; $\mathrm{AE} / \mathrm{y}=2, n=43)$, and highly frequent (hFE; $\mathrm{AE} / \mathrm{y} \geq 3, n=54)$ exacerbator groups of patients.

Life-span history of serious (emergency room access and hospitalization) [2] and near-fatal (tracheal intubation and mechanical ventilation) $\mathrm{AE}$ was also retrieved from chart data and reported.

\subsection{Evaluation of Clinical, Functional, and Blood Parameters}

Collected data included demographic parameters (age, gender, BMI, and smoking history (using $\geq 10$ pack-years as a cut-off)), clinical history with the diagnosis of comorbidities, pulmonary function tests, fractional exhaled nitric oxide (FeNO), and asthma control test (ACT) questionnaire [22,23].

We evaluated pulmonary function parameters assessing spirometry and lung volumes before and $15 \mathrm{~min}$ after albuterol administration $(400 \mu \mathrm{g})$ using body plethysmograph (Vmax Encore 62, Carefusion, Germany). FeNO was quantified using the FeNO+ instrument (Medisoft, Sorinnes, Belgium) according to the manufacturer's instruction. Chronic rhinosinusitis with (CRSwNP) or without nasal polyps (CRSsNP) and aspirin-exacerbated respiratory disease (AERD) were diagnosed according to the EPOS-2020 guideline [24].

Skin prick tests, serum total IgE levels, and consistent history identified allergic patients according to validated criteria [25]. Patients sensitized to $\geq 2$ allergens have been considered as polysensitized [26].

Blood neutrophil and eosinophil counts were performed using a Cell-Dyn Sapphire (Abbott, Rome, Italy) in routinely performed hematological examinations.

Asthma control was evaluated through the ACT questionnaire [22,23], whereas the asthma severity was classified based on the treatment strategy coded by GINA guidelines (box 7: GINA treatment steps) [20]. In particular, we referred to treatments in GINA treatment steps 1-2 as mild asthma, GINA treatment steps 3-4 as moderate asthma, and GINA treatment step 5 as severe asthma. The first item of the ACT questionnaire was used to evaluate daily activity limitations.

\subsection{Statistical Analysis}

The ROUT method was employed to detect and exclude outliers [27]. Data distributions were assessed by the D'Agostino-Pearson test to detect departure from normality. Differences between nFE and FE groups were compared using the unpaired t-test or the Mann-Whitney test. Differences between the four different exacerbation groups were compared with one-way ANOVA (with Tukey post hoc test) or Kruskal-Wallis test (with Dunn's multiple comparisons test). Chi-squared $\left(\chi^{2}\right)$ tests were used to compare frequencies. Binary logistic regression (LR) evaluated independent risk factors for the occurrence of severe AE. Results were considered statistically significant when $p<0.05$. Receiver operating characteristic (ROC) curves were used to determine optimal cut-off values of possible predictors of highly frequent exacerbation; area under the ROC curve (AUC) measured the accuracy of each score. Odds ratio (OR) was used to estimate the odds of becoming a frequent exacerbator. LR was performed with IBM SPSS Statistics 24 (IBM Corp., Armonk, NY, USA), whereas the other statistical evaluations were performed with GraphPad Prism 8.2.1 (GraphPad Software, San Diego, CA, USA).

\section{Results}

\subsection{Clinical Characteristics and Comorbidities}

The distribution of patients among groups was homogeneous in terms of both age and BMI (Table 1). Similarly, no differences in terms of smoking history were detected between $\mathrm{nFE}$ and FE patients; although a few patients in the hFE group were former smokers, none of them were current smokers. Women were more frequently FE patients $(p<0.05)$ and particularly more frequently $\mathrm{mFE}$ patients ( $p<0.01$ and $p<0.05 \mathrm{vs.} \mathrm{NE} \mathrm{and} \mathrm{OE,} \mathrm{respectively).}$ 
Table 1. Descriptive statistics of the asthmatic population.

\begin{tabular}{|c|c|c|c|c|c|c|}
\hline Demographic and Clinical Parameters & $\mathrm{nFE}(n=367)$ & FE $(n=97)$ & $\mathrm{NE}(n=248)$ & OE $(n=119)$ & $\operatorname{mFE}(n=43)$ & hFE $(n=54)$ \\
\hline Age (years) & $58.2 \pm 15.6$ & $59.9 \pm 13.9$ & $57.7 \pm 15.6$ & $59.2 \pm 15.6$ & $60.4 \pm 14.1$ & $59.5 \pm 13.8$ \\
\hline Gender (F) & $219 / 367(59.7 \%)$ & $71 / 97(73.2 \%) *$ & $145 / 248(58.5 \%)$ & $74 / 119(62.2 \%)$ & $35 / 43(81.4 \%) \# \#$ & $36 / 54(66.7 \%)$ \\
\hline BMI $\left(\mathrm{kg} / \mathrm{m}^{2}\right)$ & $27.1 \pm 5.8$ & $26.4 \pm 4.8$ & $27.2 \pm 5.9$ & $26.9 \pm 5.5$ & $25.7 \pm 4.3$ & $26.9 \pm 5.2$ \\
\hline Current smokers ( $\geq 10 \mathrm{PY})$ & $27 / 367(7.3 \%)$ & $1 / 97(1.0 \%) *$ & $19 / 248(7.7 \%)$ & $8 / 119(6.7 \%)$ & $1 / 43(2.3 \%)$ & $0 / 54(0.0 \%)$ \\
\hline Former smokers ( $\geq 10 \mathrm{PY})$ & $81 / 367(22.1 \%)$ & $18 / 97(18.6 \%)$ & $55 / 248(22.2 \%)$ & $26 / 119(21.8 \%)$ & $7 / 43(16.3)$ & $11 / 54(20.4 \%)$ \\
\hline Allergy & $193 / 367(52.6 \%)$ & $55 / 97(56.7 \%)$ & $134 / 248(54.0 \%)$ & $59 / 119(49.6 \%)$ & $24 / 43(55.8 \%)$ & $31 / 54(57.4 \%)$ \\
\hline Polysensitization & $165 / 193(85.5 \%)$ & $43 / 55(78.2 \%)$ & $117 / 134(87.3 \%)$ & $48 / 59(81.4 \%)$ & 19/24 (79.2\%) & 24/31 (77.4\%) \\
\hline Seasonal allergen sensitization & $161 / 193(83.4 \%)$ & $47 / 55(85.4 \%)$ & $114 / 134(85.1 \%)$ & $47 / 59(79.7 \%)$ & $22 / 24(91.7 \%)$ & $25 / 31(80.6 \%)$ \\
\hline Perennial allergen sensitization & $144 / 193(74.6 \%)$ & $38 / 55(69.1 \%)$ & $102 / 134(76.1 \%)$ & $42 / 59(71.2 \%)$ & $16 / 24(66.7 \%)$ & $22 / 31(71.0 \%)$ \\
\hline Mild asthma (GINA steps 1-2) & $101 / 367(27.5 \%)$ & $5 / 97(5.1 \%)^{* * *}$ & $75 / 248(30.2 \%)$ & $26 / 119(21.9 \%)$ & $3 / 43(7.0 \%){ }^{\# \#}$ & $2 / 54(3.7 \%) \# \# \S \S$ \\
\hline Moderate asthma (GINA steps 3-4) & $207 / 367(56.4 \%)$ & $48 / 97(49.5 \%)$ & $144 / 248(58.1 \%)$ & $63 / 119(52.9 \%)$ & $21 / 43(48.8 \%)$ & $27 / 54(50.0 \%)$ \\
\hline Severe asthma (GINA step 5) & $59 / 367(16.1 \%)$ & $44 / 97(45.4 \%)^{* * *}$ & $29 / 248(11.7 \%)$ & $30 / 119(25.2 \%){ }^{\# \#}$ & $19 / 43(44.2 \%) \#$ \#\# & $25 / 54(46.3 \%) \# \#$ § \\
\hline Age at asthma onset & $37.5 \pm 19.3$ & $36.5 \pm 17.1$ & $37.7 \pm 19.5$ & $37.2 \pm 19.0$ & $37.2 \pm 16.8$ & $35.9 \pm 17.5$ \\
\hline Asthma onset ( $<18$ years) & $76 / 367(20.7 \%)$ & $21 / 97(21.6 \%)$ & $54 / 248(21.8 \%)$ & $22 / 119(18.5 \%)$ & $9 / 43(20.9 \%)$ & $12 / 54(22.2 \%)$ \\
\hline Asthma duration (years) & $22.2 \pm 17.0$ & $24.9 \pm 16.5$ & $21.0 \pm 16.4$ & $22.2 \pm 16.6$ & $23.5 \pm 13.2$ & $24.4 \pm 16.9$ \\
\hline Serious asthma exacerbation history & $54 / 367(14.7 \%)$ & $31 / 97(32.0 \%)^{* * *}$ & $30 / 248(12.1 \%)$ & $24 / 119(20.2 \%)$ & $12 / 43(27.9 \%)^{\#}$ & $19 / 54(35.2 \%){ }^{\# \# \#}$ \\
\hline Near-fatal asthma exacerbation history & $3 / 54(5.6 \%)$ & $2 / 31(6.4 \%)$ & $0 / 30(0.0 \%)$ & $3 / 24(12.5 \%)$ & $1 / 12(8.3 \%)$ & $1 / 19(5.3 \%)$ \\
\hline T2-high phenotype & $293 / 366(80.0 \%)$ & $84 / 97(86.6 \%)$ & $203 / 247(82.2 \%)$ & $90 / 119(75.6 \%)$ & $35 / 43(81.4 \%)$ & $49 / 54(90.7 \%)$ \\
\hline White blood cells (cells $/ \mathrm{mm}^{2}$ ) & $7233 \pm 2091$ & $7565 \pm 1770 *$ & $7149 \pm 1816$ & $7412 \pm 2580$ & $7286 \pm 1642$ & $7788 \pm 1851$ \\
\hline Blood eosinophils (cells $/ \mathrm{mm}^{2}$ ) & $311.4 \pm 239.5$ & $325.8 \pm 282.5$ & $315.4 \pm 245.5$ & $302.8 \pm 226.7$ & $290.5 \pm 239.5$ & $353.9 \pm 312.1$ \\
\hline Blood neutrophils (cells/mm²) & $4239 \pm 1802$ & $4252 \pm 1390$ & $4116 \pm 1446$ & $4486 \pm 2362$ & $4100 \pm 1144$ & $4368 \pm 1556$ \\
\hline
\end{tabular}
Serious asthma exacerbation: emergency room access and hospitalization; near-fatal asthma exacerbation: tracheal intubation and mechanical ventilation; PY: pack-year; GINA: Global
Initiative for Asthma; T2-high: presence of allergy, blood eosinophils $>300$ cell/ $\mu \mathrm{L}$, serum IgE $>100 \mathrm{IU} / \mathrm{mL}$, or FeNO $>30 \mathrm{ppb} ;{ }^{*} p<0.05,{ }^{* * *} p<0.001 \mathrm{vs}$. nFE; ${ }^{*} p<0.05,{ }^{\# \#} p<0.01$, \#\#\# $p<0.001$ vs. NE; $\$ p<0.05$, $\$ \$ p<0.01$. 
The distribution of allergic patients in the groups was homogeneous. Likewise, no differences were detected considering the sensitization to perennial or seasonal antigens.

FE patients suffered more frequently from severe asthma than the nFE patients (OR 4.3, 95\%CI 2.6-7.1, $p<0.001$ ) and were more prone to be hospitalized due to asthma exacerbations (serious AE, OR 2.7, 95\%CI 1.6-4.5, $p<0.001$ ). Within the FE group, hFE patients were more likely to have a history of AE-related hospitalization than all the others (OR 2.8, 95\%CI 1.5-5.2, $p<0.01$ ).

Prevalence of the main comorbidities was similar among studied groups, except for nasal polyposis (CRSwNP + CRSwNP-AERD, Table 2), which were more common in the FE patients $(p<0.05)$. In particular, hFE patients suffered more frequently from nasal polyposis when compared to $\mathrm{NE}(p<0.01), \mathrm{OE}(p<0.001)$, and $\mathrm{mFE}(p<0.05)$ patients. FE had an $\mathrm{OR}=2.0(95 \% \mathrm{CI} 1.2-3.4, p<0.05)$, while $\mathrm{hFE}$ patients had an $\mathrm{OR}=3.2(95 \% \mathrm{CI} 1.7-5.9, p<0.001)$ to develop nasal polyps. Moreover, $\mathrm{hFE}$ patients had more CRSwNP than NE and OE patients $(p<0.05)$ and more CRSwNP-AERD than OE patients $(p<0.05)$. In this context, hFE patients had an OR $=2.5(95 \% \mathrm{CI} 1.2-5.0, p<0.05)$ and an OR = 3.5 (95\% CI 1.3-9.0, $p<0.05)$ to suffer CRSwNP and CRSwNP-AERD, respectively.

\subsection{Functional Parameters}

The occurrence of asthma exacerbations induced pulmonary function abnormalities. FVC \%pred and $\mathrm{FEV}_{1}$ \%pred were reduced in the FE group compared to the nFE group $(p<0.05$ and $p<0.01$, respectively; Figure 1A,B). These defective functional values were proportional to the increased number of severe AE experiences (ANOVA, $p<0.05$ ). Furthermore, a significant difference in terms of $\mathrm{FEV}_{1}$ $\%$ pred was detected between NE and hFE patients $(p<0.05)$.

A

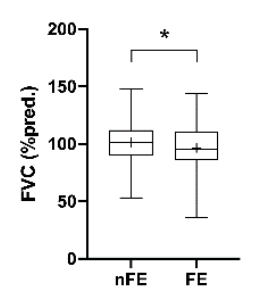

C

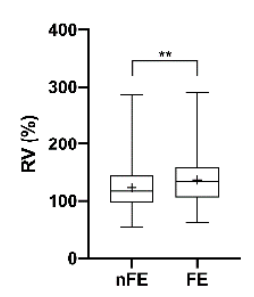

E

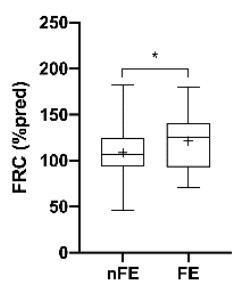

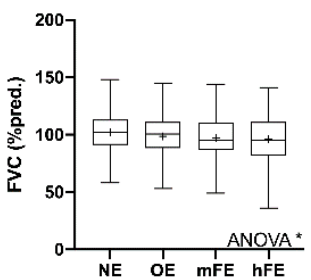
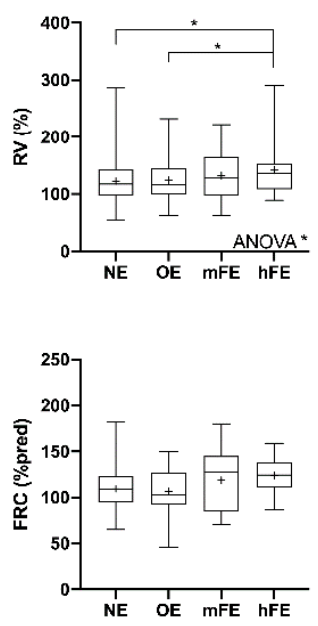

B

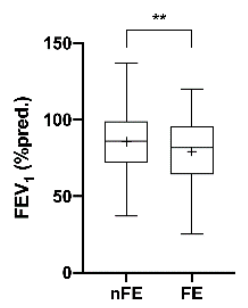

D

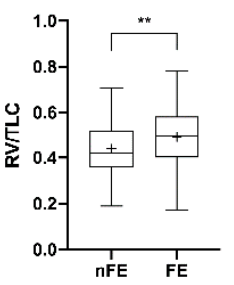

$\mathrm{F}$

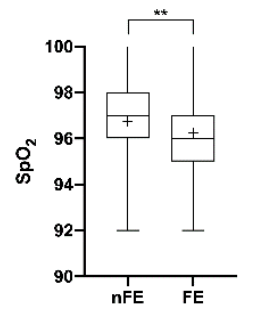

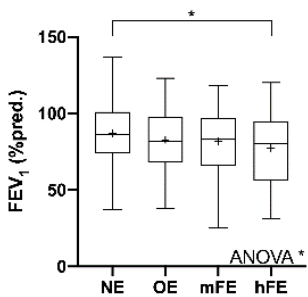
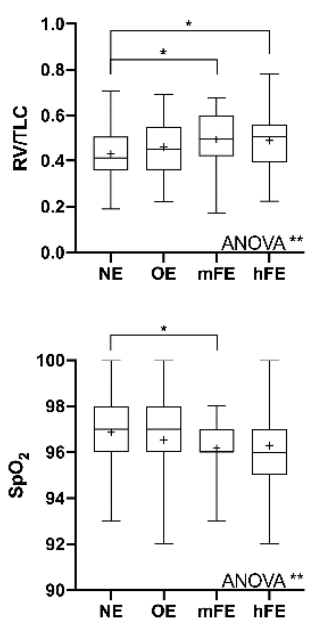

Figure 1. Functional parameters in the asthmatic population after stratification according to the number of exacerbations. (A) FVC \%pred; (B) $\mathrm{FEV}_{1} \%$ pred; (C) RV \% (\%pred); (D) RV/TLC ratio; (E) FRC \%pred; (F) blood oxygen saturation. Box plots represent data from the first to the third quartile; whiskers represent the minimum and maximum values; "+" indicates the mean value. nFE: nonfrequent exacerbator; FE: frequent exacerbator; NE: non-exacerbator; $\mathrm{OE}$ : occasional exacerbator; $\mathrm{mFE}$ : mildly frequent exacerbator; hFE: highly frequent exacerbator; ANOVA: analysis of variance. ${ }^{*} p<0.05$; ** $p<0.01$. 
Table 2. Prevalence of comorbidities in the asthmatic population.

\begin{tabular}{|c|c|c|c|c|c|c|}
\hline Comorbidities & $\mathrm{nFE}(n=367)$ & FE $(n=97)$ & $\mathrm{NE}(n=248)$ & OE $(n=119)$ & $\operatorname{mFE}(n=43)$ & hFE $(n=54)$ \\
\hline Rhinitis & $246 / 367(67.0 \%)$ & 69/97 (71.1\%) & $173 / 248(69.8 \%)$ & 73/119 (61.3\%) & $31 / 43(72.1 \%)$ & $38 / 54$ (70.4\%) \\
\hline CRSsNP & $67 / 367(18.2 \%)$ & $19 / 97(19.6 \%)$ & $43 / 248(17.3 \%)$ & $24 / 119(20.2 \%)$ & $11 / 43(25.6 \%)$ & $8 / 54(14.8 \%)$ \\
\hline CRSwNP & $41 / 367(11.2 \%)$ & $18 / 97(18.6 \%)$ & $30 / 248(12.1 \%)$ & $11 / 119(9.2 \%)$ & $5 / 43(11.6 \%)$ & $13 / 54(24.1 \%) \# \S$ \\
\hline CRSwNP-AERD & $13 / 367(3.5 \%)$ & $7 / 97(7.2 \%)$ & $11 / 248(4.4 \%)$ & $2 / 119(1.7 \%)$ & $1 / 43(2.3 \%)$ & $6 / 54(11.1 \%) \S$ \\
\hline CRSwNP + CRSwNP-AERD & $54 / 367(14.7 \%)$ & $25 / 97(25.8 \%)^{*}$ & $41 / 248(16.5 \%)$ & $13 / 119(10.9 \%)$ & $6 / 43(14.0 \%)$ & 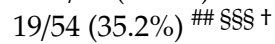 \\
\hline Bronchiectasis & $23 / 367(6.3 \%)$ & $11 / 97(11.3 \%)$ & $15 / 248(6.0 \%)$ & $8 / 119(6.7 \%)$ & $5 / 43(11.6 \%)$ & $6 / 54(11.1 \%)$ \\
\hline Pneumonia history & $39 / 367(10.6 \%)$ & $13 / 97(13.4 \%)$ & $33 / 248(13.3 \%)$ & $6 / 119(5.0 \%)$ & $6 / 43(14.0 \%)$ & $7 / 54(13.0 \%)$ \\
\hline Obstructive sleep apnea syndrome & $20 / 367(5.4 \%)$ & $4 / 97(4.1 \%)$ & $14 / 248(5.6 \%)$ & $6 / 119(5.0 \%)$ & $2 / 43(4.6 \%)$ & $2 / 54(3.7 \%)$ \\
\hline Gastroesophageal reflux disease & $85 / 367(23.2 \%)$ & $26 / 97(26.8 \%)$ & $62 / 248(25.0 \%)$ & $23 / 119(19.3 \%)$ & $13 / 43(30.2 \%)$ & $13 / 54(24.1 \%)$ \\
\hline Obesity & $89 / 367(24.2 \%)$ & $21 / 97(21.6 \%)$ & $57 / 248(23.0 \%)$ & $32 / 119(26.9 \%)$ & $6 / 43(14.0 \%)$ & $15 / 54(27.8 \%)$ \\
\hline Diabetes & $23 / 367(6.3 \%)$ & $7 / 97(7.2 \%)$ & $13 / 248(5.2 \%)$ & $10 / 119(8.4 \%)$ & $2 / 43(4.6 \%)$ & $5 / 54(9.3 \%)$ \\
\hline Hypertension & $119 / 367(32.4 \%)$ & $30 / 97(30.9 \%)$ & $85 / 248(34.3 \%)$ & $34 / 119(28.6 \%)$ & $14 / 43(32.6 \%)$ & $16 / 54(29.6 \%)$ \\
\hline Heart failure & $6 / 367(1.6 \%)$ & $2 / 97(2.1 \%)$ & $5 / 248(2.0 \%)$ & $1 / 119(0.8 \%)$ & $1 / 43(2.3 \%)$ & $1 / 53(1.8 \%)$ \\
\hline Acute myocardial infarction & $20 / 367(5.4 \%)$ & $3 / 97(3.1 \%)$ & $11 / 248(4.4 \%)$ & $9 / 119(7.6 \%)$ & $3 / 43(7.0 \%)$ & $0 / 54(0.0 \%)$ \\
\hline Arrhythmia & $27 / 367(7.4 \%)$ & $7 / 97(7.2 \%)$ & $17 / 248(6.8 \%)$ & $10 / 119(8.4 \%)$ & $3 / 43(7.0 \%)$ & $4 / 54(7.4 \%)$ \\
\hline Anxiety depression syndrome & $52 / 367(14.2 \%)$ & $14 / 97(14.4 \%)$ & $35 / 248(14.1 \%)$ & $17 / 119(14.3 \%)$ & $8 / 43(18.6 \%)$ & 6/54 (11.1\%) \\
\hline Osteoporosis & $31 / 397(8.4 \%)$ & $6 / 97(6.2 \%)$ & $20 / 248(8.1 \%)$ & $11 / 119(9.2 \%)$ & $2 / 43(4.6 \%)$ & $4 / 54(7.4 \%)$ \\
\hline Arthropathy & $31 / 367(8.4 \%)$ & 9/97 (9.3\%) & $18 / 248(7.3 \%)$ & $13 / 119(10.9 \%)$ & $2 / 43(4.6 \%)$ & $7 / 54(13.0 \%)$ \\
\hline Chronic pain & $23 / 367(5.9 \%)$ & $7 / 97(7.2 \%)$ & $13 / 248(5.2 \%)$ & $10 / 119(8.4 \%)$ & $3 / 43(7.0 \%)$ & $4 / 54(7.4 \%)$ \\
\hline
\end{tabular}

CRSsNP: chronic rhinosinusitis without nasal polyposis; CRSwNP: chronic rhinosinusitis with nasal polyposis; CRSwNP-AERD: chronic rhinosinusitis with nasal polyposis and aspirin-exacerbated respiratory disease; ${ }^{*} p<0.05 \mathrm{vs}$. nFE; ${ }^{\#} p<0.05,{ }^{\# \#} p<0.01 \mathrm{vs}$. NE; ${ }^{\S} p<0.05,{ }^{\$} \S \$<0.001 \mathrm{vs}$. OE; ${ }^{\dagger} p<0.05 \mathrm{vs}$. mFE. 
RV \%pred, RV/TLC ratio, and FRC \%pred were increased ( $p<0.01, p<0.01$, and $p<0.05$, respectively) in FE patients in comparison to $\mathrm{nFE}$ patients (Figure 1C-E). Analysis of variance detected significant increments in RV \%pred $(p<0.05)$ and RV/TLC ratio $(p<0.01)$ but only a trend $(p=0.064)$ in regard to FRC \%pred. RV was higher in hFE patients than in those belonging to NE and OE groups (both $p<0.05$ ), while the RV/TLC was greater in both mFE and hFE groups than in the NE group (both $p<0.05$ ).

No differences in terms of $\mathrm{FEV}_{1} / \mathrm{FVC}$ ratio (\%) and TLC \%pred were detected among evaluated groups, nor were differences detected concerning volume and flow changes $(\mathrm{mL})$ of FVC and $\mathrm{FEV}_{1}$ after bronchodilation (Table S1).

Although no differences were detected considering the heart rate of patients (Table S1), blood oxygen saturation levels $\left(\mathrm{SpO}_{2}\right)$ decreased as the number of $\mathrm{AE} / \mathrm{y}$ increased (Figure 1F). FE patients had lower $\mathrm{SpO}_{2}$ than $\mathrm{nFE}$ ones $(p<0.01)$, and there was a progressive $\mathrm{SpO}_{2}$ reduction from $\mathrm{NE}$ to $\mathrm{hFE}$ patients (ANOVA, $p<0.01$ ).

\subsection{Asthma Control}

Daily activity limitations (DALs) were more common in FE patients than nFE patients $(p<0.001$; Figure 2A). Limitation occurrences were proportional to the AE/y: hFE patients had more impairments than the others $(p<0.05, p<0.01$, and $p<0.001$ versus $\mathrm{mFE}, \mathrm{OE}$, and NE, respectively), whereas activities were more limited in $\mathrm{mFE}$ and OE patients than in NE patients $(p<0.001$ and $p<0.05$, respectively). No differences were detected between $\mathrm{mFE}$ and OE patients. Considering a DAL score $\leq 3$ as a threshold, we detected that FE patients were more prone (41.2\%) to develop limitations than the $\mathrm{nFE}$ ones $(18.0 \%$, OR $=3.2,95 \% \mathrm{CI} 1.9-5.2, p<0.001)$. Furthermore, hFE patients suffered from a worse situation $(48.2 \%)$ than the others $(19.5 \%$, OR $=3.8,95 \% \mathrm{CI} 2.1-6.9, p<0.001)$.

FE patients suffered more frequently from uncontrolled asthma than nFE patients $(p<0.001$; Figure 2B). Results of ACT worsened with the increase of AE/y $(p<0.001)$. Well-controlled asthma was more frequent in NE, while few cases were present in the hFE group; the OE and $\mathrm{mFE}$ groups had a comparable percentage of well-controlled patients. Partially controlled asthma was common in the NE and OE groups. In contrast, the percentage of patients who had uncontrolled asthma increased progressively from the NE to the hFE group, in which the percentage was at its maximum.

A

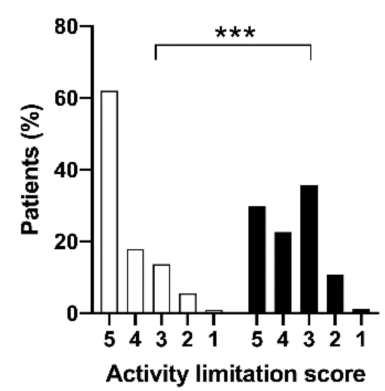

B

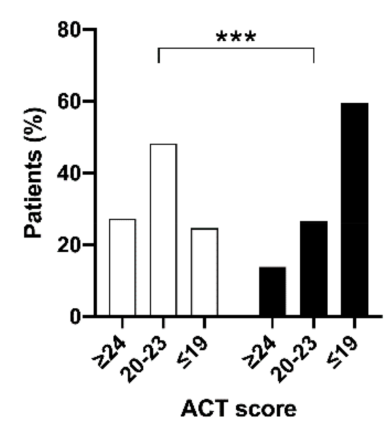

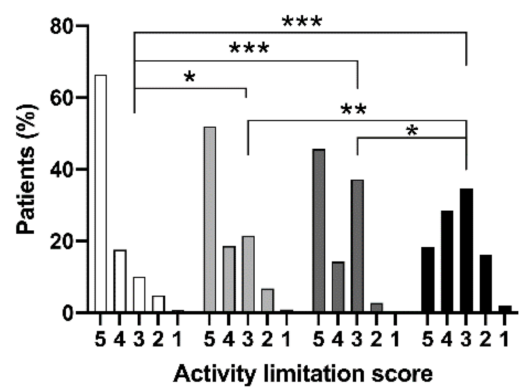

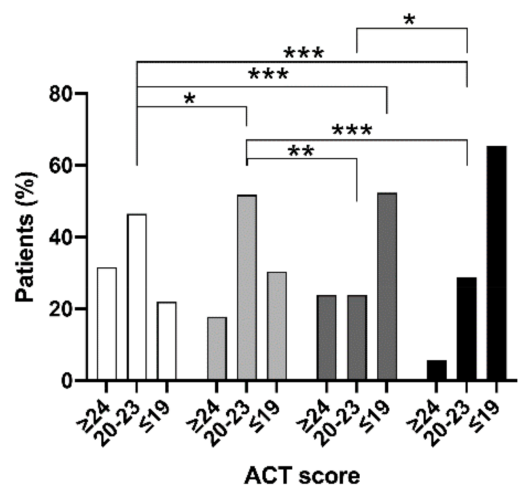

Figure 2. Cont. 

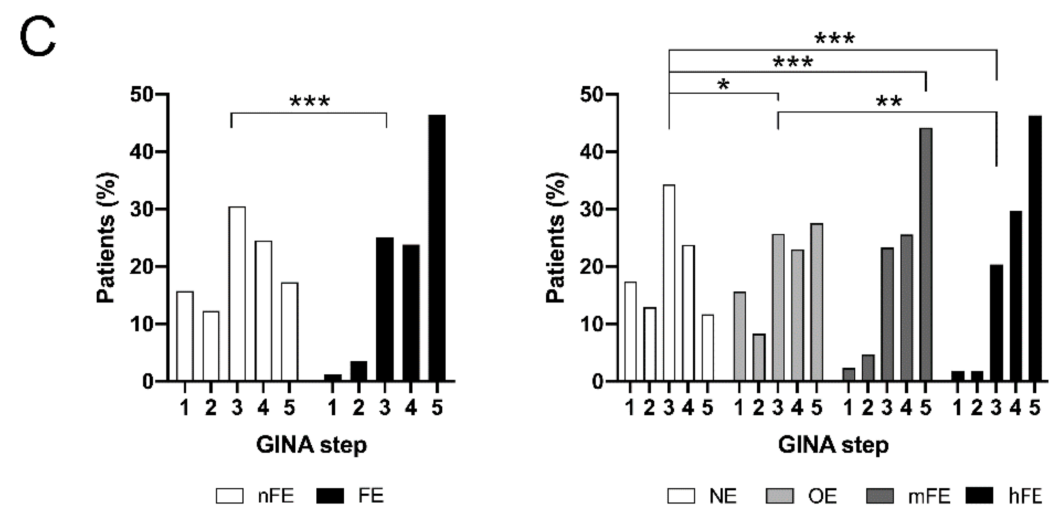

Figure 2. Asthma control in the asthmatic population after stratification according to the number of exacerbations. Results of (A) limitations to daily activity and (B) asthma control test (ACT) improve as scores increase. (C) The resulting treatment step according to Global Initiative for Asthma (GINA) improves as score decreases. ${ }^{*} p<0.05 ;{ }^{* *} p<0.01 ;{ }^{* * *} p<0.001$.

\subsection{Asthma Treatment}

FE patients were classified predominantly as belonging to the GINA treatment step 5 and, to a lesser extent, were also classified as steps 3 and 4 . Otherwise, nFE patients were mainly classified as step 3 ( $p<0.001$; Figure 2C) [20]. Higher GINA treatment step classifications were characteristic of $\mathrm{hFE}$ and mFE groups. Among them, the hFE group showed higher GINA treatment step classifications than the OE group $(p<0.01)$, whereas NE patients showed a milder classification than the others $(p<0.01$ vs. OE and $p<0.001$ vs. $\mathrm{mFE}$ and hFE).

FE patients received higher doses of ICS than nFE patients $(p<0.001$; Table 3). Treatment of $\mathrm{hFE}$ and $\mathrm{mFE}$ patients required ICS doses higher than those administered to OE patients $(p<0.001$ and $p<0.05$, respectively). The lowest doses were given to NE patients ( $p<0.001 \mathrm{vs.} \mathrm{hFE} \mathrm{and} \mathrm{mFE}$ and $p<0.01$ vs. OE). Moreover, hFE patients underwent OCS treatment more frequently than those of the other groups ( $p<0.05 \mathrm{vs.} \mathrm{mFE,} p=0.075 \mathrm{vs.} \mathrm{OE}$, and $p<0.001 \mathrm{vs}$. NE). FE patients used long-acting $\beta_{2}$ agonists (LABA) and/or long acting-muscarinic antagonists (LAMA) more frequently $(p<0.001$ and $p<0.05$, respectively) than nFE patients. The hFE group used more LABA than the OE $(p<0.01)$ and NE $(p<0.001)$ groups and used more LAMA than the NE group $(p<0.05)$, whereas mFE patients used more LABA than NE patients $(p<0.01)$. Differences in biological drug administration were detected only for mepolizumab, which was given more frequently to $\mathrm{FE}(p<0.001)$ and, in particular, hFE patients than those belonging to $\mathrm{OE}(p<0.01)$ or NE $(p<0.001)$ groups.

Table 3. Pharmacological treatments in the asthmatic population.

\begin{tabular}{|c|c|c|c|c|c|c|}
\hline Treatment & $\begin{array}{c}\text { nFE } \\
(n=367)\end{array}$ & FE $(n=97)$ & NE $(n=248)$ & OE $(n=119)$ & $\operatorname{mFE}(n=43)$ & hFE $(n=54)$ \\
\hline ICS & $\begin{array}{l}307 / 367 \\
(83.6 \%)\end{array}$ & $95 / 97(97.9 \%)^{* * *}$ & $\begin{array}{l}205 / 248 \\
(82.7 \%)\end{array}$ & $102 / 119(85.7 \%)$ & $42 / 43(97.7 \%)^{\#}$ & $53 / 54(98.1 \%) \# \#$ \\
\hline $\begin{array}{c}\text { ICS/day } \\
(\mu \mathrm{g} \text { BDP-HFA) }\end{array}$ & $263.5 \pm 201$ & $446.4 \pm 237.6^{* * *}$ & $239.1 \pm 176$ & $314.3 \pm 238.0^{\# \#}$ & $\begin{array}{c}423.3 \pm 235.9 \\
\# \# \text { § }\end{array}$ & 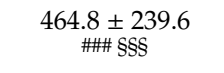 \\
\hline LABA & $\begin{array}{l}265 / 397 \\
(72.2 \%)\end{array}$ & $92 / 97(94.8 \%)^{* * *}$ & $\begin{array}{l}172 / 248 \\
(69.4 \%)\end{array}$ & $93 / 119(78.2 \%)$ & $40 / 43(93.0 \%) \#$ & $52 / 54(96.3 \%) \# \#$ $\S \S$ \\
\hline LAMA & $\begin{array}{c}56 / 367 \\
(15.3 \%)\end{array}$ & $25 / 97(25.8 \%) *$ & $\begin{array}{c}37 / 248 \\
(14.9 \%)\end{array}$ & $19 / 119(16.0 \%)$ & $9 / 43(20.9 \%)$ & $16 / 54(29.6 \%)^{\#}$ \\
\hline $\begin{array}{c}\text { OCS } \\
(\geq 6 \text { months/year })\end{array}$ & $9 / 367(2.4 \%)$ & $7 / 97(7.2 \%)$ & $4 / 248(1.6 \%)$ & $5 / 119(4.2 \%)$ & $0 / 43(0.0 \%)$ & 7/54 (13.0\%) \#\#\# † \\
\hline Omalizumab & $18 / 367(4.9 \%)$ & 9/88 (9.3\%) & $12 / 248(4.8 \%)$ & $6 / 119(5.0 \%)$ & $6 / 43(14.0 \%)$ & $3 / 54(5.6 \%)$ \\
\hline Mepolizumab & $7 / 367$ (1.9\%) & $13 / 97(13.4 \%)^{* * *}$ & $3 / 248(1.2 \%)$ & $4 / 119(3.4 \%)$ & $3 / 43(7.0 \%)$ & $10 / 54$ (18.5\%) \#\#\# §§ \\
\hline
\end{tabular}

ICS: inhaled corticosteroids; BDP-HFA: beclomethasone dipropionate HFA; LABA: long-acting beta-agonists; LAMA: long-acting muscarinic antagonists; OCS: oral corticosteroids; * $p<0.05$, *** $p<0.001$ vs. nFE; $\# p<0.05,{ }^{\# \#} p<0.01$, \#\# $p<0.001$ vs. NE; $\S^{\prime} p<0.05, \$ \S p<0.01$, $\$ \$ \$ p<0.001$ vs. OE; ${ }^{\dagger} p<0.05$ vs. mFE. 


\subsection{T2-High Biomarkers}

FE patients had higher levels of white blood cells (WBC) $(p<0.05)$, but no differences in terms of blood neutrophil or blood eosinophil counts were detected among the analyzed groups (Table 1 , Figure S1). Nevertheless, levels of IgE in the blood of FE patients were higher than those in $\mathrm{nFE}$ patients $(p<0.05)$, as the hFE group had significantly higher levels than the other groups $(p<0.001$; Figure 3A). Similarly, FeNO was higher in FE $(p<0.05)$ patients than in $\mathrm{nFE}$ patients due to the higher concentrations detected in hFE patients ( $p<0.001$ against all the other groups; Figure 3B).

A

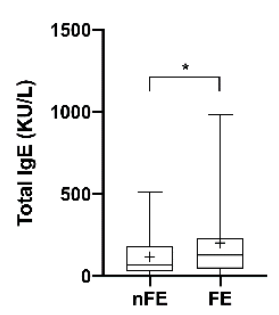

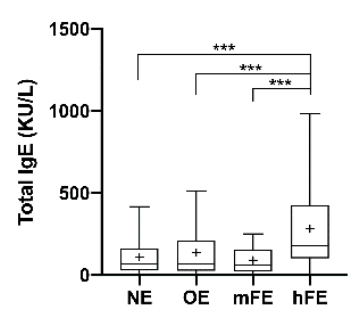

B

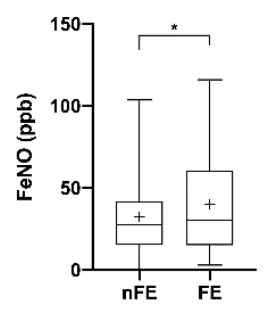

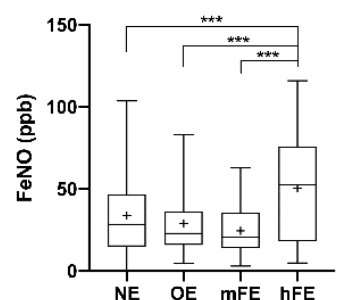

$\mathrm{C}$

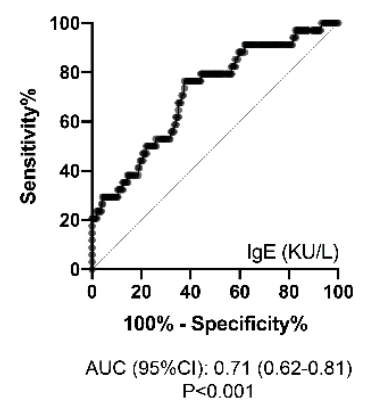

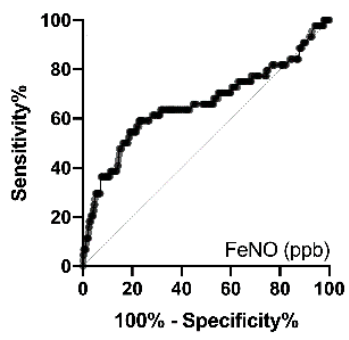

AUC (95\%Cl): $0.66(0.56-0.76)$

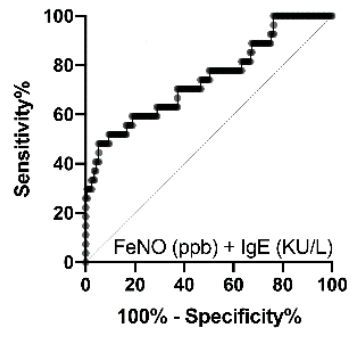

AUC (95\%Cl): $0.74(0.63-0.85)$

Figure 3. T2 biomarkers in the asthmatic population after stratification according to the number of exacerbations: (A) serum IgE concentrations, (B) FeNO values, and (C) their respective and cumulative ROC curve analyses. Box plots represent data from the first to the third quartile; whiskers represent the minimum and maximum values; " + " indicates the mean value. ${ }^{*} p<0.05 ;{ }^{* * *} p<0.001$.

Thus, the hFE group was compared to all the other categories combined, and ROC curve analyses allowed the detection of possible cut-off values (Figure 3C). Patients with serum total IgE concentration $>107.5 \mathrm{kU} / \mathrm{L}$ had almost 4 times the odds to belong to the hFE group (OR 4.1 (95\%CI 1.7-8.8); $p<0.001$ ); sensitivity was $93.6 \%$, specificity $21.6 \%$, PPV $54.6 \%$, and NPV 77.1\%. Furthermore, patients with FeNO levels $>43.35 \mathrm{ppb}$ had more than 3-fold the probability to be hFE patients (OR 3.8 (95\%CI 2.0-7.1); $p<0.001$ ); sensitivity was $93.1 \%$, specificity $21.8 \%$, PPV $72.2 \%$, and NPV $59.1 \%$. ROC curve analyses of the cumulative probability obtained by combining serum IgE and FeNO concentrations through the LR formula

$$
P=\frac{1}{1+e^{-[-3.819+(0.026 \times F e N O ~ p p b)+(0.005 \times I g E k U / L)},}
$$

allowed us to detect that patients with value of $P>0.2522$ were about 16 times more likely to be hFE patients (OR 16.5 [95\%CI 5.9-45.4]; $p<0.001$ ); sensitivity was $92.0 \%$, specificity $59.1 \%$, PPV 97.7\%, and NPV $48.2 \%$.

\section{Discussion}

In this study, we analyzed the characteristics of 464 patients suffering from mild to severe asthma. Based on $\mathrm{AE} / \mathrm{y}$, we classified patients as either nonfrequent (nFE) or frequent exacerbator (FE) patients, further subdividing them into non- (NE), occasional (OE), mildly frequent (mFE), and highly frequent exacerbator (hFE) groups. Clinically, we detected that FE patients are often women and suffered more frequently from sinusitis and nasal polyposis. Similarly, pulmonary function and $\mathrm{SpO}_{2}$ were 
hampered in FE patients, with consequent daily activity limitations. Exacerbating patients had a higher probability of suffering from severe asthma and had a history of serious AE. FE patients also had poor asthma control. Therefore, their treatment included ICS (with or without LAMA and LABA) at higher doses than those administered to nFE patients and frequently included OCS or mepolizumab. The therapeutic strategy (GINA treatment step) varied according to the shift from NE to hFE. FE patients had a higher count of WBC than their more controlled counterparts, although levels of neutrophils and eosinophils were comparable between the two populations. Interestingly, hFE patients had higher levels of serum IgE and FeNO than the other groups. Using ROC curves, we detected possible cut-off values able, alone or in combination, to predict the probability of belonging to the $\mathrm{hFE}$ group.

Although BMI and age have been described as factors having a role in AE occurrence, they did not appear to be involved in our cohort. This discrepancy could be mainly due to the mean age (57.7 to 60.4 years) and BMI (25.7 and 27.2) within our groups, which were higher than risk thresholds reported in the literature (age $>45$ years and $\mathrm{BMI} \approx 23.5$ ) $[28,29]$. Gender differences are otherwise present and in accord with the literature: patients affected by frequent exacerbation are often women, who generally are more susceptible because of hormone-mediated mechanisms [30,31]. However, after a further stratification according to the number of $\mathrm{AE} / \mathrm{y}$, the gender ratio of $\mathrm{hFE}$ patients became similar to those of patients belonging to the $\mathrm{nFE}$ groups (NE and OE). The unbalance detected in the $\mathrm{mFE}$ group is not fully understood and could be related to the higher mean age in this population (60.4 years), but further analyses are still required. Finally, cigarette smoking history did not promote the onset of severe AE significantly in our population, and thus it cannot be considered as a risk factor. It should be noted that there were fewer former smokers and no current smokers present in the more exacerbating hFE group.

As the number of exacerbations increased, progressive deterioration in lung function occurred. In particular, FE patients exhibited greater airway obstruction at both proximal (airflow limitation as determined by reduced $\mathrm{FEV}_{1}$ ) and peripheral levels (air trapping as determined by lower FVC and higher RV and RV/TLC ratio; lung hyperinflation as determined by increased FRC) than the nonfrequent ones. This condition could be the cause of the reduced $\mathrm{SpO}_{2}$ detected in FE patients, confirming the respiratory pathophysiology axiom. Lack of alteration regarding heart rate could be explained by the $\mathrm{SpO}_{2}$ remaining, on average, higher than $96 \%$.

The main consequence of lung function deterioration was daily activity limitations, which represent the first clinical sign of respiratory disability. Impairments affected OE and $\mathrm{mFE}$ patients, but they had a greater impact on hFE patients. Activity limitation is more common in FE (OR 3.2) than nFE patients, where patients classified as hFE had the highest probability (OR 3.8). In this context, it should be taken into consideration that there is a psychological component that can increase the intensity of the perceived limitation [32].

Asthma severity and control in FE patients were predominantly worsened and thus required high-intensity pharmacological treatment [20]. Patients suffering from numerous AE/y often required therapeutic strategies classifiable in higher GINA treatment steps (above all in step 5). Despite these treatments, FE patients were more prone (OR 2.7) to have a history of serious exacerbation (hospitalization, ICU stay, or mechanical ventilation) [2] than $\mathrm{nFE}$ patients. The hFE patient remains that with the highest probability of hospitalization (OR 2.8).

Mepolizumab treatment was more frequent in FE patients than in $\mathrm{nFE}$ patients. However, we detected three NE patients and four OE patients in treatment since 2017. These patients met the mepolizumab eligibility [33] at the beginning of the treatment. Otherwise, no significant changes in terms of omalizumab administration have been detected. This is likely because the frequency of atopy was similar between patient groups, which were comparable in terms of sensitization to perennial and seasonal allergens.

Therapy against IL-5 hampers eosinophil maturation, activation, and survival, whereas the corticosteroid therapy causes eosinophil apoptosis, favoring the switch to a more neutrophilic phenotype of asthma when administered at the highest dose [34]. No changes have been observed in terms of both blood eosinophils and neutrophils between FE and nFE patients, despite the administration 
of higher corticosteroid doses and mepolizumab in FE patients. Otherwise, a significant increment of WBC in FE patients was evident, possibly due to the subclinical respiratory infection [35] or systemic inflammation [36] that underlies the severe AE occurrence.

On the basis of these findings, the high-intensity pharmacological treatment apparently dissociated eosinophil count from the other T2 biomarkers. The anti-IL- 5 treatment reduces eosinophil count but does not affect IgE concentrations and FeNO values [37,38], which are modulated by the IL4/13 signaling $[39,40]$. Indeed, the predominance of a T2-high inflammatory status is evident above all in the most exacerbating hFE group. These patients were characterized by a higher incidence of nasal polyposis (OR 3.2), a potential eosinophilic-derived disease [41], and higher concentrations of serum total IgE and FeNO than those belonging to the other groups.

Detection of these two biomarkers predicts exacerbation [18,42]; it can be useful to discriminate patients at higher risk of developing frequently severe AE. In particular, we detected that serum IgE concentrations and FeNO values greater than $107.5 \mathrm{kU} / \mathrm{L}$ and $43.35 \mathrm{ppb}$ are moderate predictors of belonging to the hFE group (OR 4.1 and 3.8, respectively). Nevertheless, their cumulative probability (when $P>0.2522$ ) provides better results and is a more reliable predictor (OR 16.1). We may also infer that FE patients could express a combination of T2 and Th17 immune response in the airways, as previously demonstrated $[18,43,44]$.

\section{Conclusions}

The main limitations of this study are represented by the real-life design and the intrinsic characteristics of our population, consisting mainly of adult and elderly patients. In this point of view, there is a conflict with the previous literature in that differences in age, BMI, and, to some extent, gender may have been underestimated.

In conclusion, we described the characteristics of asthmatic patients prone to various degrees of asthma exacerbation. In particular, we highlight the highly frequent exacerbator as a phenotype with the worst prognosis due to a high probability of developing respiratory disability and a history of serious exacerbations that required hospitalization. Nevertheless, elevated FeNO and IgE levels characterized the hFE phenotype and are likely exploitable for its identification, allowing the appropriate therapeutic approach.

Supplementary Materials: The following are available online at http://www.mdpi.com/2077-0383/9/7/2226/s1, Figure S1: Blood eosinophils and blood neutrophils in the asthmatic population, Table S1: Other functional parameters in the asthmatic population.

Author Contributions: F.L.M.R. conceived, designed, and is the guarantor of the study; A.E.S., V.C., S.L., C.B., and F.B. contributed to data collection and analysis; A.E.S., V.C., and F.L.M.R. drafted the manuscript; A.D.S., M.M., and G.C. critically commented on and reviewed the manuscript. All authors have read and agreed to the published version of the manuscript.

Funding: This research received no external funding.

Acknowledgments: This study was supported by the "Ricerca Locale 2019" fund (RILO19) of University of Turin.

Conflicts of Interest: The authors declare that no conflicts of interest exist.

\section{References}

1. Reddel, H.K.; Taylor, D.R.; Bateman, E.D.; Boulet, L.P.; Boushey, H.A.; Busse, W.W.; Casale, T.B.; Chanez, P.; Enright, P.L.; Gibson, P.G.; et al. An official American Thoracic Society/European Respiratory Society statement: Asthma control and exacerbations: Standardizing endpoints for clinical asthma trials and clinical practice. Am. J. Respir. Crit. Care Med. 2009, 180, 59-99. [CrossRef] [PubMed]

2. Chung, K.F.; Wenzel, S.E.; Brozek, J.L.; Bush, A.; Castro, M.; Sterk, P.J.; Adcock, I.M.; Bateman, E.D.; Bel, E.H.; Bleecker, E.R.; et al. International ERS/ATS guidelines on definition, evaluation and treatment of severe asthma. Eur. Respir. J. 2014, 43, 343-373. [CrossRef] [PubMed]

3. Graham, L.M.; Eid, N. The impact of asthma exacerbations and preventive strategies. Curr. Med. Res. Opin. 2015, 31, 825-835. [CrossRef] [PubMed] 
4. Accordini, S.; Corsico, A.G.; Braggion, M.; Gerbase, M.W.; Gislason, D.; Gulsvik, A.; Heinrich, J.; Janson, C.; Jarvis, D.; Jogi, R.; et al. The cost of persistent asthma in Europe: An international population-based study in adults. Int. Arch. Allergy Immunol. 2013, 160, 93-101. [CrossRef] [PubMed]

5. Bloom, C.I.; Nissen, F.; Douglas, I.J.; Smeeth, L.; Cullinan, P.; Quint, J.K. Exacerbation risk and characterisation of the UK's asthma population from infants to old age. Thorax 2018, 73, 313-320. [CrossRef]

6. Holguin, F.; Cardet, J.C.; Chung, K.F.; Diver, S.; Ferreira, D.S.; Fitzpatrick, A.; Gaga, M.; Kellermeyer, L.; Khurana, S.; Knight, S.; et al. Management of severe asthma: A European Respiratory Society/American Thoracic Society guideline. Eur. Respir. J. 2020, 55, 1900588. [CrossRef]

7. Agache, I.; Akdis, C.; Jutel, M.; Virchow, J.C. Untangling asthma phenotypes and endotypes. Allergy 2012, 67, 835-846. [CrossRef]

8. Bel, E.H.; Sousa, A.; Fleming, L.; Bush, A.; Chung, K.F.; Versnel, J.; Wagener, A.H.; Wagers, S.S.; Sterk, P.J.; Compton, C.H.; et al. Diagnosis and definition of severe refractory asthma: An international consensus statement from the Innovative Medicine Initiative (IMI). Thorax 2011, 66, 910-917. [CrossRef]

9. Zeiger, R.S.; Schatz, M.; Li, Q.; Chen, W.; Khatry, D.B.; Gossage, D.; Tran, T.N. High blood eosinophil count is a risk factor for future asthma exacerbations in adult persistent asthma. J. Allergy Clin. Immunol. Pract. 2014, 2, 741-750. [CrossRef]

10. Green, R.H.; Brightling, C.E.; McKenna, S.; Hargadon, B.; Parker, D.; Bradding, P.; Wardlaw, A.J.; Pavord, I.D. Asthma exacerbations and sputum eosinophil counts: A randomised controlled trial. Lancet 2002, 360, 1715-1721. [CrossRef]

11. Kupczyk, M.; ten Brinke, A.; Sterk, P.J.; Bel, E.H.; Papi, A.; Chanez, P.; Nizankowska-Mogilnicka, E.; Gjomarkaj, M.; Gaga, M.; Brusselle, G.; et al. Frequent exacerbators-a distinct phenotype of severe asthma. Clin. Exp. Allergy. 2014, 44, 212-221. [CrossRef] [PubMed]

12. Price, D.B.; Rigazio, A.; Campbell, J.D.; Bleecker, E.R.; Corrigan, C.J.; Thomas, M.; Wenzel, S.E.; Wilson, A.M.; Small, M.B.; Gopalan, G.; et al. Blood eosinophil count and prospective annual asthma disease burden: A UK cohort study. Lancet Respir. Med. 2015, 3, 849-858. [CrossRef]

13. Edris, A.; De Feyter, S.; Maes, T.; Joos, G.; Lahousse, L. Monoclonal antibodies in type 2 asthma: A systematic review and network meta-analysis. Respir. Res. 2019, 20, 179. [CrossRef] [PubMed]

14. Denlinger, L.C.; Phillips, B.R.; Ramratnam, S.; Ross, K.; Bhakta, N.R.; Cardet, J.C.; Castro, M.; Peters, S.P.; Phipatanakul, W.; Aujla, S.; et al. Inflammatory and Comorbid Features of Patients with Severe Asthma and Frequent Exacerbations. Am. J. Respir. Crit. Care Med. 2017, 195, 302-313. [CrossRef] [PubMed]

15. Norzila, M.Z.; Fakes, K.; Henry, R.L.; Simpson, J.; Gibson, P.G. Interleukin-8 secretion and neutrophil recruitment accompanies induced sputum eosinophil activation in children with acute asthma. Am. J. Respir. Crit. Care Med. 2000, 161 Pt 1, 769-774. [CrossRef]

16. Vedel-Krogh, S.; Fallgaard Nielsen, S.; Lange, P.; Vestbo, J.; Nordestgaard, B.G. Association of Blood Eosinophil and Blood Neutrophil Counts with Asthma Exacerbations in the Copenhagen General Population Study. Clin. Chem. 2017, 63, 823-832. [CrossRef]

17. Irvin, C.; Zafar, I.; Good, J.; Rollins, D.; Christianson, C.; Gorska, M.M.; Martin, R.J.; Alam, R. Increased frequency of dual-positive TH2/TH17 cells in bronchoalveolar lavage fluid characterizes a population of patients with severe asthma. J. Allergy Clin. Immunol. 2014, 134, 1175-1186. [CrossRef]

18. Bullone, M.; Carriero, V.; Bertolini, F.; Folino, A.; Mannelli, A.; Di Stefano, A.; Gnemmi, I.; Torchio, R.; Ricciardolo, F.L.M. Elevated serum IgE, oral corticosteroid dependence and IL-17/22 expression in highly neutrophilic asthma. Eur. Respir. J. 2019, 54, 1900068. [CrossRef]

19. Castillo, J.R.; Peters, S.P.; Busse, W.W. Asthma Exacerbations: Pathogenesis, Prevention, and Treatment. J. Allergy Clin. Immunol. Pract. 2017, 5, 918-927. [CrossRef]

20. Global Initiative for Asthma. Global Strategy for Asthma Management and Prevention. Available online: www.ginasthma.org (accessed on 8 December 2019).

21. Carriero, V.; Bertolini, F.; Sprio, A.E.; Bullone, M.; Ciprandi, G.; Ricciardolo, F.L.M. High levels of plasma fibrinogen could predict frequent asthma exacerbations. J. Allergy Clin. Immunol. Pract. 2020, 8, 2392-2395. [CrossRef]

22. Meltzer, E.O.; Schatz, M.; Nathan, R.; Garris, C.; Stanford, R.H.; Kosinski, M. Reliability, validity, and responsiveness of the Rhinitis Control Assessment Test in patients with rhinitis. J. Allergy Clin. Immunol. 2013, 131, 379-386. [CrossRef] [PubMed] 
23. Nathan, R.A.; Sorkness, C.A.; Kosinski, M.; Schatz, M.; Li, J.T.; Marcus, P.; Murray, J.J.; Pendergraft, T.B. Development of the asthma control test: A survey for assessing asthma control. J. Allergy Clin. Immunol. 2004, 113, 59-65. [CrossRef]

24. Fokkens, W.J.; Lund, V.J.; Mullol, J.; Bachert, C.; Alobid, I.; Baroody, F.; Cohen, N.; Cervin, A.; Douglas, R.; Gevaert, P.; et al. European Position Paper on Rhinosinusitis and Nasal Polyps 2012. Rhinol. Suppl. 2012, 23, $1-298$.

25. Muraro, A.; Roberts, G.; Halken, S.; Agache, I.; Angier, E.; Fernandez-Rivas, M.; Gerth van Wijk, R.; Jutel, M.; Lau, S.; Pajno, G.; et al. EAACI guidelines on allergen immunotherapy: Executive statement. Allergy 2018, 73, 739-743. [CrossRef]

26. Hellings, P.W.; Fokkens, W.J.; Bachert, C.; Akdis, C.A.; Bieber, T.; Agache, I.; Bernal-Sprekelsen, M.; Canonica, G.W.; Gevaert, P.; Joos, G.; et al. Positioning the principles of precision medicine in care pathways for allergic rhinitis and chronic rhinosinusitis-A EUFOREA-ARIA-EPOS-AIRWAYS ICP statement. Allergy 2017, 72, 1297-1305. [CrossRef]

27. Motulsky, H.J.; Brown, R.E. Detecting outliers when fitting data with nonlinear regression-A new method based on robust nonlinear regression and the false discovery rate. BMC Bioinform. 2006, 7, 123. [CrossRef] [PubMed]

28. Kang, H.R.; Song, H.J.; Nam, J.H.; Hong, S.H.; Yang, S.Y.; Ju, S.; Lee, S.W.; Kim, T.B.; Kim, H.L.; Lee, E.K. Risk factors of asthma exacerbation based on asthma severity: A nationwide population-based observational study in South Korea. BMJ Open 2018, 8, e020825. [CrossRef]

29. Ohta, K.; Tanaka, H.; Tohda, Y.; Kohrogi, H.; Chihara, J.; Sakakibara, H.; Adachi, M.; Tamura, G. Asthma exacerbations in patients with asthma and rhinitis: Factors associated with asthma exacerbation and its effect on QOL in patients with asthma and rhinitis. Allergol. Int. 2019, 68, 470-477. [CrossRef] [PubMed]

30. Fuseini, H.; Newcomb, D.C. Mechanisms Driving Gender Differences in Asthma. Curr. Allergy Asthma Rep. 2017, 17, 19. [CrossRef] [PubMed]

31. Zein, J.G.; Erzurum, S.C. Asthma is Different in Women. Curr. Allergy Asthma Rep. 2015, 15, 28. [CrossRef]

32. Vermeulen, F.; Chirumberro, A.; Rummens, P.; Bruyneel, M.; Ninane, V. Relationship between the sensation of activity limitation and the results of functional assessment in asthma patients. J. Asthma 2017, 54, 570-577. [CrossRef]

33. Albers, F.C.; Mullerova, H.; Gunsoy, N.B.; Shin, J.Y.; Nelsen, L.M.; Bradford, E.S.; Cockle, S.M.; Suruki, R.Y. Biologic treatment eligibility for real-world patients with severe asthma: The IDEAL study. J. Asthma 2018, 55, 152-160. [CrossRef] [PubMed]

34. Cowan, D.C.; Cowan, J.O.; Palmay, R.; Williamson, A.; Taylor, D.R. Effects of steroid therapy on inflammatory cell subtypes in asthma. Thorax 2010, 65, 384-390. [CrossRef] [PubMed]

35. Denlinger, L.C.; Heymann, P.; Lutter, R.; Gern, J.E. Exacerbation-Prone Asthma. J. Allergy Clin. Immunol. Pract. 2019, 8, 474-482. [CrossRef]

36. Silvestri, M.; Bontempelli, M.; Giacomelli, M.; Malerba, M.; Rossi, G.A.; Di Stefano, A.; Rossi, A.; Ricciardolo, F.L. High serum levels of tumour necrosis factor-alpha and interleukin-8 in severe asthma: Markers of systemic inflammation? Clin. Exp. Allergy 2006, 36, 1373-1381. [CrossRef] [PubMed]

37. Ortega, H.; Chupp, G.; Bardin, P.; Bourdin, A.; Garcia, G.; Hartley, B.; Yancey, S.; Humbert, M. The role of mepolizumab in atopic and nonatopic severe asthma with persistent eosinophilia. Eur. Respir. J. 2014, 44, 239-241. [CrossRef]

38. Pavord, I.D.; Korn, S.; Howarth, P.; Bleecker, E.R.; Buhl, R.; Keene, O.N.; Ortega, H.; Chanez, P. Mepolizumab for severe eosinophilic asthma (DREAM): A multicentre, double-blind, placebo-controlled trial. Lancet 2012, 380, 651-659. [CrossRef]

39. Ricciardolo, F.L.M.; Silkoff, P.E. Perspectives on exhaled nitric oxide. J. Breath Res. 2017, 11, 47104. [CrossRef]

40. Gandhi, N.A.; Pirozzi, G.; Graham, N.M.H. Commonality of the IL-4/IL-13 pathway in atopic diseases. Expert Rev. Clin. Immunol. 2017, 13, 425-437. [CrossRef]

41. Zervas, E.; Samitas, K.; Papaioannou, A.I.; Bakakos, P.; Loukides, S.; Gaga, M. An algorithmic approach for the treatment of severe uncontrolled asthma. ERJ Open Res. 2018, 4, 00125-2017. [CrossRef]

42. Ricciardolo, F.L. Revisiting the role of exhaled nitric oxide in asthma. Curr. Opin. Pulm. Med. 2014, $20,53-59$. [CrossRef] [PubMed] 
43. Ricciardolo, F.L.M.; Sorbello, V.; Folino, A.; Gallo, F.; Massaglia, G.M.; Favata, G.; Conticello, S.; Vallese, D.; Gani, F.; Malerba, M.; et al. Identification of IL-17F/frequent exacerbator endotype in asthma. J. Allergy Clin. Immunol. 2017, 140, 395-406. [CrossRef] [PubMed]

44. Sorbello, V.; Ciprandi, G.; Di Stefano, A.; Massaglia, G.M.; Favata, G.; Conticello, S.; Malerba, M.; Folkerts, G.; Profita, M.; Rolla, G.; et al. Nasal IL-17F is related to bronchial IL-17F/neutrophilia and exacerbations in stable atopic severe asthma. Allergy 2015, 70, 236-240. [CrossRef] [PubMed]

(C) 2020 by the authors. Licensee MDPI, Basel, Switzerland. This article is an open access article distributed under the terms and conditions of the Creative Commons Attribution (CC BY) license (http://creativecommons.org/licenses/by/4.0/). 